\title{
Early markers are present in both embryogenesis pathways from microspores and immature zygotic embryos in cork oak, Quercus suber L
}

Héctor Rodríguez-Sanz , José-Antonio Manzanera², María-Teresa Solís ${ }^{1}$, Aránzazu Gómez-Garay ${ }^{3}$, Beatriz Pintos ${ }^{3}$, María C Risueño ${ }^{1}$ and Pilar S Testillano ${ }^{1 *}$

\begin{abstract}
Background: In Quercus suber, cork oak, a Mediterranean forest tree of economic and social interest, rapid production of isogenic lines and clonal propagation of elite genotypes have been achieved by developing in vitro embryogenesis from microspores and zygotic embryos respectively. Despite its high potential in tree breeding strategies, due to their recalcitrancy, the efficiency of embryogenesis in vitro systems in many woody species is still very low since factors responsible for embryogenesis initiation and embryo development are still largely unknown. The search for molecular and cellular markers during early stages of in vitro embryogenesis constitutes an important goal to distinguish, after induction, responsive from non-responsive cells, and to elucidate the mechanisms involved in embryogenesis initiation for their efficient manipulation. In this work, we have performed a comparative analysis of two embryogenesis pathways derived from microspores and immature zygotic embryos in cork oak in order to characterize early markers of reprogrammed cells in both pathways. Rearrangements of the cell structural organization, changes in epigenetic marks, cell wall polymers modifications and endogenous auxin changes were analyzed at early embryogenesis stages of the two in vitro systems by a multidisciplinary approach.

Results: Results showed that early embryo cells exhibited defined changes of cell components which were similar in both embryogenesis in vitro systems, cellular features that were not found in non-embryogenic cells. DNA methylation level and nuclear pattern, proportion of esterified pectins in cell walls, and endogenous auxin levels were different in embryo cells in comparison with microspores and immature zygotic embryo cells from which embryos originated, constituting early embryogenesis markers.
\end{abstract}

Conclusions: These findings suggest that DNA hypomethylation, cell wall remodeling by pectin esterification and auxin increase are involved in early in vitro embryogenesis in woody species, providing new evidences of the developmental pattern similarity between both embryogenesis pathways, from microspores and immature zygotic embryos, in woody species.

Keywords: Somatic embryogenesis, Microspore embryogenesis, Anther culture, DNA methylation, 5-methyl-deoxy-cytidine, Pectin esterification, Cell wall, Auxin, IAA

\footnotetext{
* Correspondence: testillano@cib.csic.es

${ }^{1}$ Pollen Biotechnology of Crop Plants group, Biological Research Center,

CIB-CSIC, Ramiro de Maeztu 9, 28040 Madrid, Spain

Full list of author information is available at the end of the article
} 


\section{Background}

In vitro embryogenesis systems constitute important tools for investigating the regulating mechanisms of embryo formation, as well as for biotechnological applications in plant breeding, propagation and conservation strategies. Two different embryogenesis pathways, from microspores and immature zygotic embryos, have been developed in many species for rapid production of isogenic lines and clonal propagation of elite genotypes respectively. Tree breeding strategies have focused on ways to reduce cycle time and improve the efficiency of selection; here, propagation of selected trees by somatic embryogenesis and genetic engineering approaches applied to haploids and double-haploid plants produced in short-times by in vitro microspore embryogenesis have a high potential. Nevertheless, due to their recalcitrance, the efficiency of embryogenesis in vitro systems in many woody species is still very low.

Quercus trees, oaks, are woody species of relevant economic and ecological interest; among them the cork oak, Q. suber, is a species of high social and economic relevance in the Mediterranean area as the natural source of cork. Different in vitro embryogenesis systems have been developed for Quercus spps., with variable efficiency [1-3]. Despite the work performed in the last decades, factors responsible for embryogenesis initiation and embryo development in established cultures are still largely unknown.

The search for molecular and cellular markers during early stages of in vitro embryogenesis constitutes an important goal in the identification of cells committed to the embryogenesis developmental program as opposed to those cells which are non-responsive to the embryogenic pathway, as well as in the elucidation of the cellular mechanisms underlying in vitro embryo progression. Changes in various cell activities and in the structural organization of subcellular compartments have been reported as accompanying the microspore reprogramming process in some herbaceous and woody species [4-11]. Increasing evidences have indicated the relevance of some cell features like epigenetic marks [12-15], cell wall components [10,16-19] and hormones [9] in the progression of in vitro organogenesis and embryogenesis in other systems, but no reports about the dynamics of these three cellular markers during in vitro early embryogenesis are available in two somatic embryogenesis pathways of the same species.

Dynamic changes between chromatin states are relevant in the transcriptional regulation during microspore development and reprogramming to embryogenesis [6] and epigenetic mechanisms play an essential role in the process of cellular differentiation allowing cells to be reprogrammed in order to generate new differentiation pathways [12]. DNA methylation constitutes a prominent epigenetic modification of the chromatin fiber, which becomes locked in a transcriptionally inactive conformation, thus leading to gene silencing. Stress-induced plant cell reprogramming involves changes in global genome organization, being the epigenetic modifications key factors of genome flexibility [13]. Previous studies have shown changes in DNA methylation levels and distribution patterns during microspore embryogenesis of Brassica napus and Hordeum vulgare [14,15], suggesting the existence of an epigenetic reprogramming after microspore induction to embryogenesis, but no information is available on DNA methylation dynamics during in vitro embryogenesis in trees.

Many of the molecular markers of in vitro embryogenesis and organogenesis have been found in cell walls [10,16-19]. Pectins are the major matrix components of dicotyledonous cell walls. Pectins are polymerized and methyl-esterified in the Golgi, and secreted into the wall as highly methyl-esterified forms. Subsequently, they can be modified by pectin methylesterases, which catalyse the demethylesterification of homogalacturonans domains of pectins. The relationship between the esterified and the non-esterified pectins, and their distribution in the plant cell walls is the result of different processes [20-22] and their proportion and dynamics are involved in many plant developmental processes. Changes in the distribution of pectins have been reported in young embryos generated from microspores of Quercus suber L. [8], Citrus clementina [23] and Olea europaea L. [10]. Abundant esterified pectins has been reported in the newly-formed walls of proliferating cells in different plant systems, like young microspore-derived embryos and root tip meristematic cells of herbaceous species $[17,18]$, suggesting that a high proportion of esterified pectins in walls is a marker for proliferation events while abundant low-esterified pectins correspond to low cell proliferation rates $[17,18]$.

The plant growth regulator (PGR) auxin, the predominant form of which is indole-3-acetic acid (IAA), is a major coordinating signal in the regulation of plant development, with key functions in many processes including embryo formation [24,25]. Despite it is widely known the stimulating effects of the addition of exogenous PGRs, including synthetic auxins like 2,4-D, on in vitro embryogenesis induction $[9,26]$, little is known about endogenous levels of these regulators at the initial stages of embryogenesis. In cork oak somatic embryos, the quantification of IAA showed the highest concentration during early embryo development and decreased afterwards [27]. Recent work has reported preliminary results showing that endogenous IAA localized in cells of early multicellular embryos developed in isolated microspore cultures of Brassica napus [28].

Previous reports have indicated that microspore embryogenesis mimics zygotic embryogenesis in several 
species $[7,9,14,29]$. Proteomic analyses have approached the identification of protein expression patterns in $Q$. suber embryos originated by different in vitro systems during advanced developmental stages and maturation $[30,31]$. The phytohormones can act as signaling molecules for remodeling cell walls during cell elongation, as well as for modifying chromatin domains to activate gene expression programs. In this sense, the information about the dynamics of epigenetic marks, pectin esterification changes in walls and auxin during early embryogenesis could inform on possible correlations among these processes, giving new insights into the complex regulatory mechanisms controlling cell reprogramming and embryogenesis induction.

In the present work, we have performed a comparative analysis of in vitro embryogenesis of microspores and immature zygotic embryos in cork oak in order to characterize early markers of embryo cells, in contrast with non-responsive cells, in both pathways and to gain new insights into the cellular mechanisms involved in the in vitro embryogenesis induction in woody species, in which there is scarce information, as well as to provide new evidences of the developmental pattern similarity between both embryogenesis pathways, from microspores and zygotic embryos. We have analyzed the changes in DNA methylation, esterification of pectins in cell walls and endogenous auxin distribution, during early embryogenesis of the two in vitro systems.

The results presented here revealed differential features in early multicellular embryo cells constituting early embryogenic markers which are similar in both pathways originated from microspores and zygotic embryos, providing additional evidences to the developmental pattern analogy of embryogenesis pathways.

\section{Results}

Characterization of early developmental stages of embryogenesis of both microspore and zygotic embryo origins in Quercus suber

Two different embryogenic in vitro systems have been compared in cork oak, embryogenesis of microspores (through anther culture) and immature zygotic embryos, to analyze the presence and distribution patterns of various cellular components at early embryogenesis stages and to identify common markers present in the two embryogenic pathways at the initial stages.

Microspore embryogenesis was induced by heat treatment in anthers excised from catkins (Figure 1A) at the developmental stage in which they contained microspores at the responsive stage of vacuolated microspores. After 20 25 days in culture, white small multicellular and globular embryos emerged from inside the anther (Figure 1B, C); these embryos further developed to heart, torpedo and cotyledonary embryos. Mature cotyledonary embryos produced by microspore embryogenesis were subcultured monthly on medium without growth regulators producing embryogenic masses ("ms" in Figure 1D) from which new embryos emerged by secondary embryogenesis (arrow in Figure 1D).

Microscopic analysis of culture samples at early developmental stages showed small multicellular embryos ("emb" in Figure 1E) of different sizes inside the anthers and emerging out of the them. The early multicellular embryos originated by either direct or secondary embryogenesis showed a typical structural organization consisting in a more or less rounded structure formed by small cells, with characteristic features of active proliferating cells. The cells of these so-called early multicellular embryos were small, with medium-large nucleus, slightly dense cytoplasm and low vacuolation ("emb" in Figure 1E, F, G), very different from the cells of the anther wall tissues ("AW" in Figure 1E) and embryogenic masses ("ms" in Figure 1F, G) which were of larger size and highly vacuolated.

Immature pollinated acorns (Figure $1 \mathrm{H}$ ) were the source of zygotic embryos which were cultured and used for somatic embryogenesis induction. Around one month after the culture initiation, early multicellular embryos of various sizes and globular embryos were observed on the surface of the immature zygotic embryos, they later developed to produce heart, torpedo and cotyledonary embryos (Figure 1I). Embryos were transferred to proliferating medium where secondary embryogenesis was observed and after repetitive subcultures the existing embryos could proliferate by producing embryogenic masses ("ms" in Figure 1J) from which new embryos were originated (arrow in Figure 1J).

The cells of early multicellular embryos of this somatic embryogenesis system showed a similar structural organization than those of the microspore embryogenesis pathway, early embryo cells exhibited small size, dense cytoplasm with small vacuoles and a mid-size nucleus ("emb" in Figure $1 \mathrm{~K}, \mathrm{~L}$ ), clearly distinguishable from the larger cells displayed by the immature zygotic embryo which exhibited a large vacuole ("zye" in Figure $1 \mathrm{~K}$ ). Secondary embryos of microspore and somatic origin emerged and developed from the embryogenic masses as small multicellular embryos ("emb" in Figure 1M) formed by cells which exhibited similar organization than described for cells of early multicellular embryos directly originated from microspores or immature zygotic embryos, very different than the larger and highly vacuolated cells of the embryogenic masses ("ms" in Figure 1M).

\section{DNA methylation changes during early embryogenesis of} both microspore and zygotic embryo origins

The percentage of global DNA methylation was analyzed at different developmental stages of embryogenesis as well as in microspores and zygotic embryos (Figure 2). The 

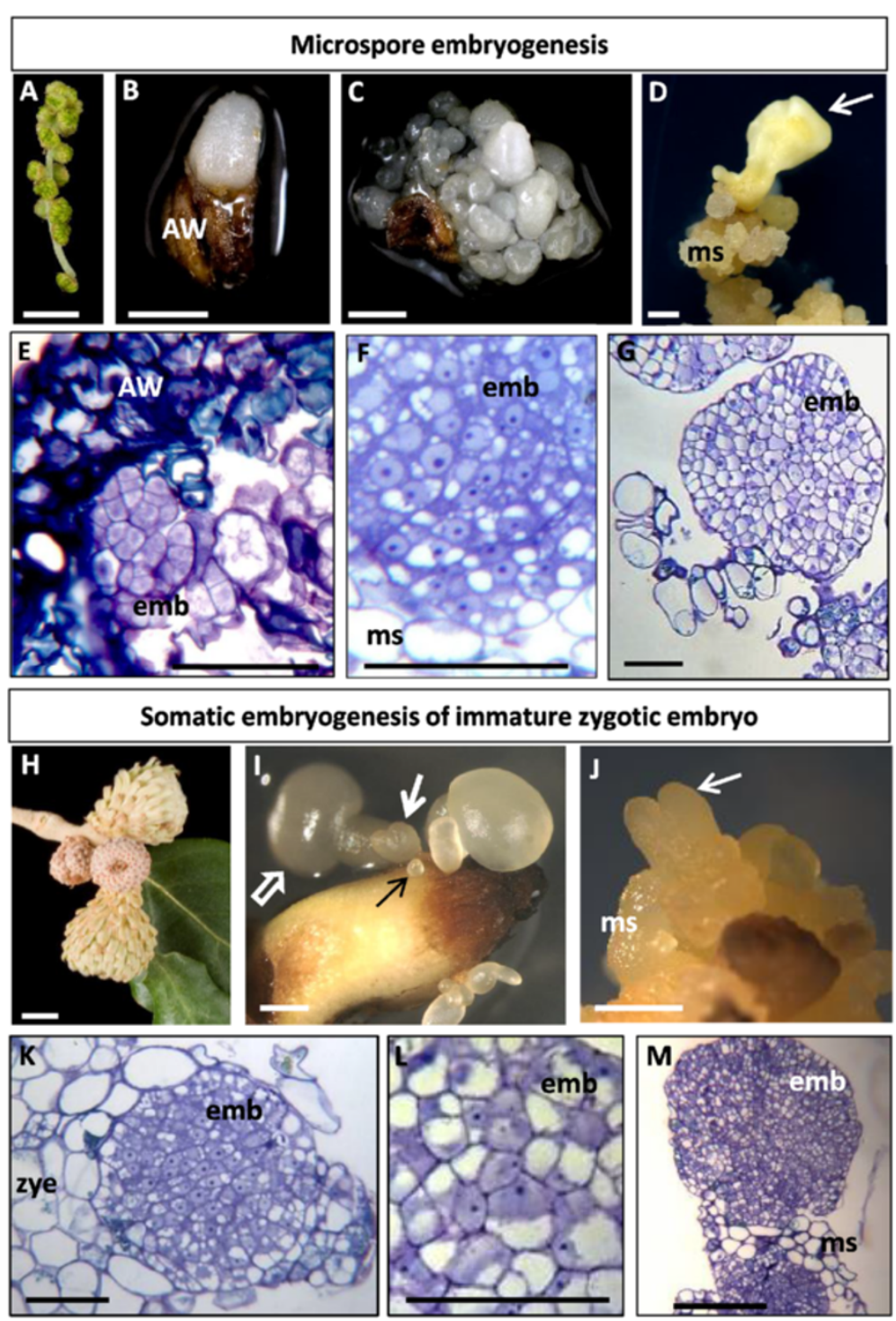

Figure 1 Main developmental stages of in vitro embryogenesis in cork oak. A-G: Microspore embryogenesis. H-M: Somatic embryogenesis of immature zygotic embryos. A-D, H-J: Explants and in vitro embryo development. E-G, K-M: Different stages of embryo development, resin sections stained by toluidine blue. A: Catkin selected for in vitro microspore embryogenesis. B, C: Multicellular and globular embryos (white structures) of different sizes emerging from inside anthers (AW, anther wall) after 20-30 days in culture. D: Secondary embryo (white arrow) emerging from embryogenic masses (ms). E: Early multicellular embryos (emb) formed inside the anther and surrounded by the tissue of the anther wall (AW). F: Cells of an early multicellular embryo at higher magnification. G: Large multicellular embryo formed by secondary embryogenesis attached to some cells of an embryogenic mass (ms). $\mathbf{H}$ : Acorn selected for in vitro somatic embryogenesis of immature zygotic embryos. I: Embryos of different developmental stages and sizes emerging from the immature zygotic embryo explant after 30 days in culture, early multicellular embryo (black thin arrow), globular, heart (white thick arrow) and cotyledonary (white open arrow) embryos. J: Secondary embryo (white arrow) at the torpedo stage originated from embryogenic masses (ms). K: Early multicellular embryo (emb) formed at the surface of an immature zygotic embryo (zye). L: Cells of an early multicellular embryo at higher magnification. M: Early multicellular embryos (emb) formed by secondary embryogenesis and emerging from inside an embryogenic mass (ms). Bars: A, H: 100 m; B, C, D, I, J: 1 mm; E, F, GK, L: $50 \mu \mathrm{m} ; \mathbf{M :} 200 \mu \mathrm{m}$.

results of the quantification showed similar temporal DNA methylation profiles in both embryogenesis pathways. DNA methylation significantly decreased $(p \leq 0.05)$ after embryogenesis induction, in early multicellular embryos, in comparison with microspores in anthers, and zygotic embryos before embryogenesis initiation. At later embryogenesis stages DNA methylation levels significantly increased $(p \leq 0.05)$ in heart and torpedo embryos, and during late embryo development, reaching the highest level in cotyledonary embryos in the two in vitro systems (Figure 2). In heart-torpedo embryos of the second pathway, derived from zygotic embryos, the increase in global 


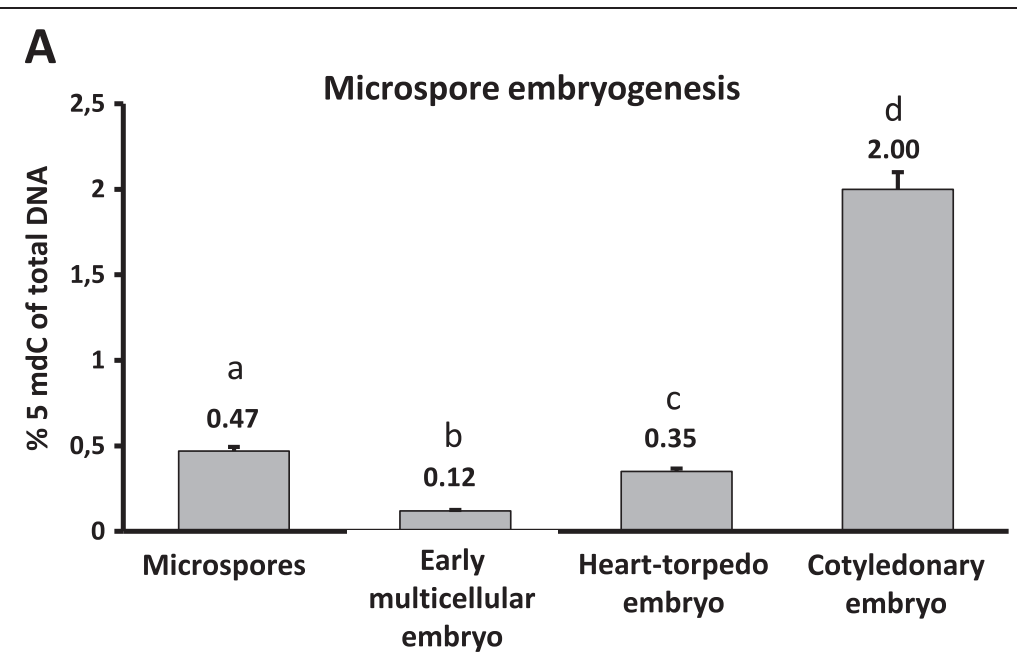

\section{B}

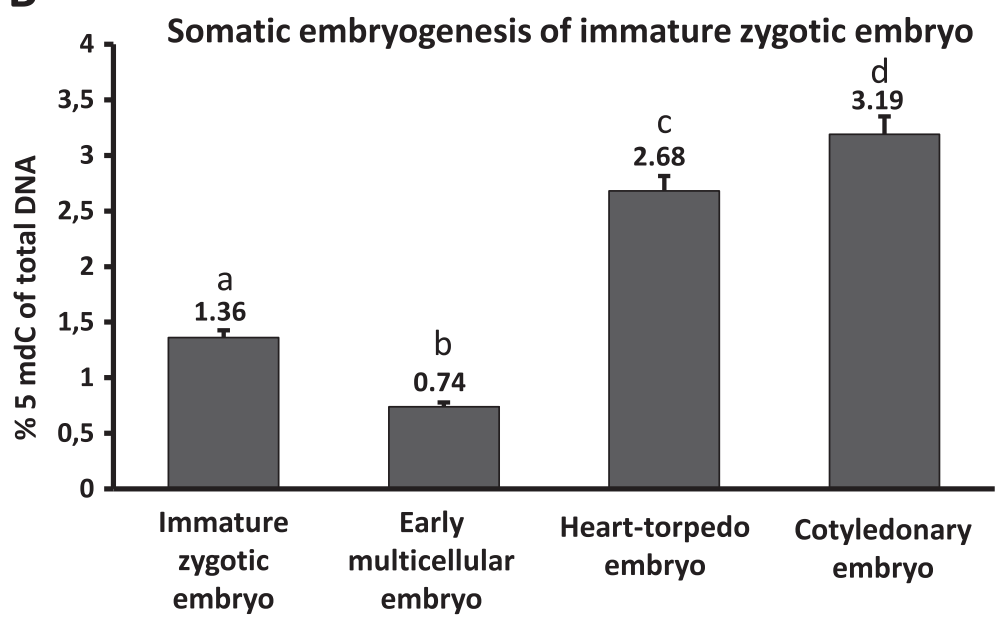

Figure 2 Global DNA methylation during in vitro embryogenesis of microspore and immature zygotic embryo. Histograms representing the mean values of $5 \mathrm{mdC}$ percentage of total DNA in different stages of microspore embryogenesis (A) and somatic embryogenesis of immature zygotic embryos (B), quantified by ELISA-based immunoassay. Bars on columns represent the standard errors of the means. Different letters on columns indicate significant differences according to ANOVA and Tukey's test at $P \leq 0.05$.

DNA methylation was higher than in the microspore embryogenesis pathway.

To analyze the changes in the nuclear distribution pattern of methylated DNA during early embryogenesis, immunofluorescence with anti-5mdC antibody followed by confocal analysis was performed at early stages of both primary and secondary embryogenesis, specifically at the stage of early multicellular embryos in the two pathways studied, microspores and immature zygotic embryos. The $5 \mathrm{mdC}$ immunofluorescence signal was similar in early multicellular embryo cells of the two embryogenesis pathways (Figure 3) and in primary and secondary embryos. The $5 \mathrm{mdC}$ immunofluorescence signal was very different in early embryo cells than inf microspores of anthers (Figure 3D, D'), immature zygotic embryos ("zye" in Figure 3H, H', H", I, I') and embryogenic masses ("ms" in
Figure 3A, A, C, C, C", E, E, G, G', G”). Early multicellular embryos directly originated from in vitro microspore or zygotic embryo cultures by primary embryogenesis showed the same $5 \mathrm{mdC}$ pattern of localization than multicellular embryos ("emb" in Figure 3A, A', E, E') produced from embryogenic masses ("ms" in Figure 3A, A, E, E') by secondary embryogenesis in the two pathways. Early embryo cells displayed a distribution pattern of $5 \mathrm{mdC}$ immunofluorescence in small bright spots over the nucleus, which were clearly identified by DAPI staining (Figure 3, B, B', B", , F, F', F"), these $5 \mathrm{mdC}$ fluorescence spots probably correspond to small heterochromatin masses. On the contrary, nuclei of microspores (Figure 3D, D'), immature zygotic embryos ("zye" in Figure 3H, H', H", I, I') and embryogenic masses (Figure 3C, C', C", G, G'. G") showed an intense $5 \mathrm{mdC}$ immunofluorescence signal which covered 


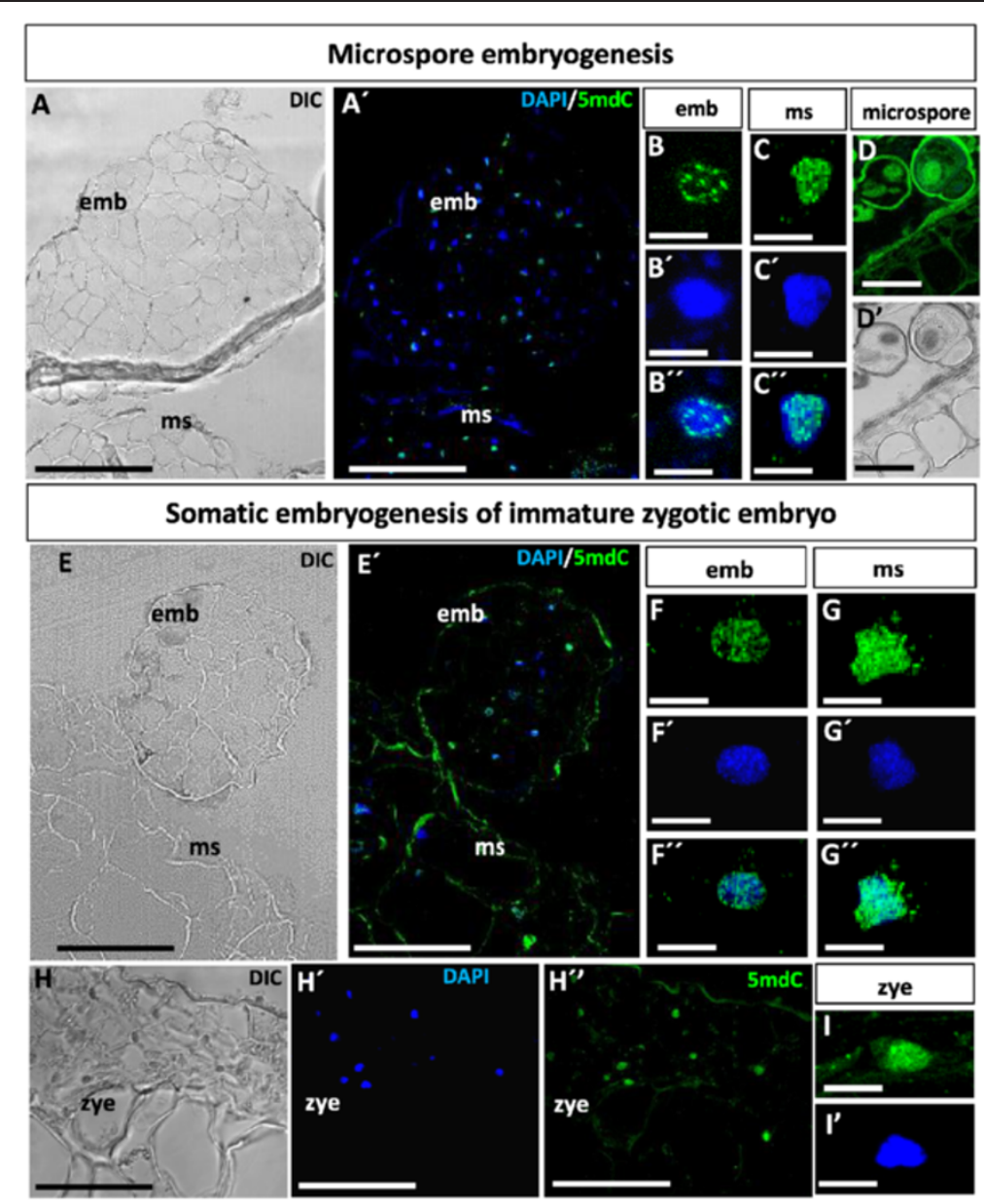

Figure 3 Methylated DNA nuclear patterns at early in vitro embryogenesis of microspore and immature zygotic embryo. A-D Microspore embryogenesis. E-I: Somatic embryogenesis of immature zygotic embryos. A, A', E, E': Confocal images of 5 mdC immunofluorescence in early multicellular embryos (emb) and embryogenic masses (ms). Differential interference contrast, DIC, images (A, E), and merged images of 5 mdC immunofluorescence (green) and DAPI staining (blue) for the nuclei $\left(\mathbf{A}^{\prime}, \mathbf{E}^{\prime}\right)$ of the same sections. B-B", C-C', F-F", G-G": High magnification images of representative nuclei of early multicellular embryos, "emb" (B-B", F-F"), embryogenic masses, "ms" (C-C", G-G"), microspores (D, D') and immature zygotic embryos, "zye" (I, I') showing $5 \mathrm{mdC}$ immunofluorescence in green (B, C, D,F, G, I), DAPI staining of nuclei in blue (B', $\mathbf{C}^{\prime}$, $\mathbf{F}^{\prime}, \mathbf{G}^{\prime}, \mathbf{I}^{\prime}$ ) and merged images of both green and blue channels (B", $\left.\mathbf{C}^{\prime \prime}, \mathbf{F}^{\prime \prime}, \mathbf{G}^{\prime \prime}\right)$. Bars: A, A', E, E': $50 \mu \mathrm{m} ; \mathbf{B}, \mathbf{B}^{\prime}, \mathbf{B}^{\prime \prime}, \mathbf{C}, \mathbf{C}^{\prime}, \mathbf{C}^{\prime \prime}, \mathbf{F}^{\prime}, \mathbf{F}^{\prime}, \mathbf{F}^{\prime \prime}, \mathbf{G}^{\prime}, \mathbf{G}^{\prime}, \mathbf{G}^{\prime \prime}, \mathbf{I}, \mathbf{I}^{\prime}$ : $5 \mu \mathrm{m} ; \mathbf{D}, \mathbf{D}^{\prime}: 10 \mu \mathrm{m}$.

almost the entire nuclear region. The exine, the special pollen wall, showed unspecific autofluorescence (Figure 3D) which did not interfere with the specific immunofluorescence signals detected throughout the microspore embryogenesis analysis. Control experiments avoiding the first antibody or the denaturation step, required for $5 \mathrm{mdC}$ recognition by the antibody, did not show labeling in any sample and developmental stage, assessing the specificity of the antibody.

Changes in pectin esterification of cell walls during early embryogenesis of both microspore and zygotic embryo origins

The changes in the proportion of pectin esterification in the cell walls during early stages of embryogenesis of microspore and zygotic embryos were analyzed by using
JIM5 and JIM7 specific antibodies, which recognize nonesterified and highly-esterified pectins respectively, in immunodot-blot and immunofluorescence assays. Dotblot analysis was performed in microspores and zygotic embryos before embryogenesis induction as well as in embryos during consecutive developmental stages of both embryogenic pathways. The differences in the signal intensities of dot-blots, which were performed over equal amounts of protein extracts, as illustrated by the Ponceau red staining, revealed changes in the proportion of highly-esterified and non-esterified pectins of cell walls during embryogenesis (Figure 4A, B). The quantification of the signal intensities showed similar temporal profiles in the two embryogenesis pathways for each antibody (Figure 4C, D, E, F). JIM5 signal, corresponding to non-esterified pectins, was high in microspores and 
zygotic embryos before induction whereas it progressively diminished with embryogenesis progression in heart, torpedo and cotyledonary embryos (Figure 4C, E); in the microspore embryogenesis pathway, the lowering of JIM5 signal was significant also at earlier stages, in multicellular embryos (Figure 4C, E). On the contrary, JIM7 antibody which recognizes highly-esterified pectins, showed a significant signal increase $(p \leq 0.05)$ in early multicellular embryos in comparison with microspores and immature zygotic embryos (Figure 4D, F). The intensities of JIM7 signals at advanced embryogenesis stages progressively decreased, in heart, torpedo and cotyledonary embryos (Figure 4D, F). Control experiments avoiding the first antibodies did not show labeling in any case.

Immunofluorescence assays revealed analogous localization patterns in both embryogenesis pathways from microspore and immature zygotic embryos for each pectin epitope, non-esterified (JIM5 labelling) and

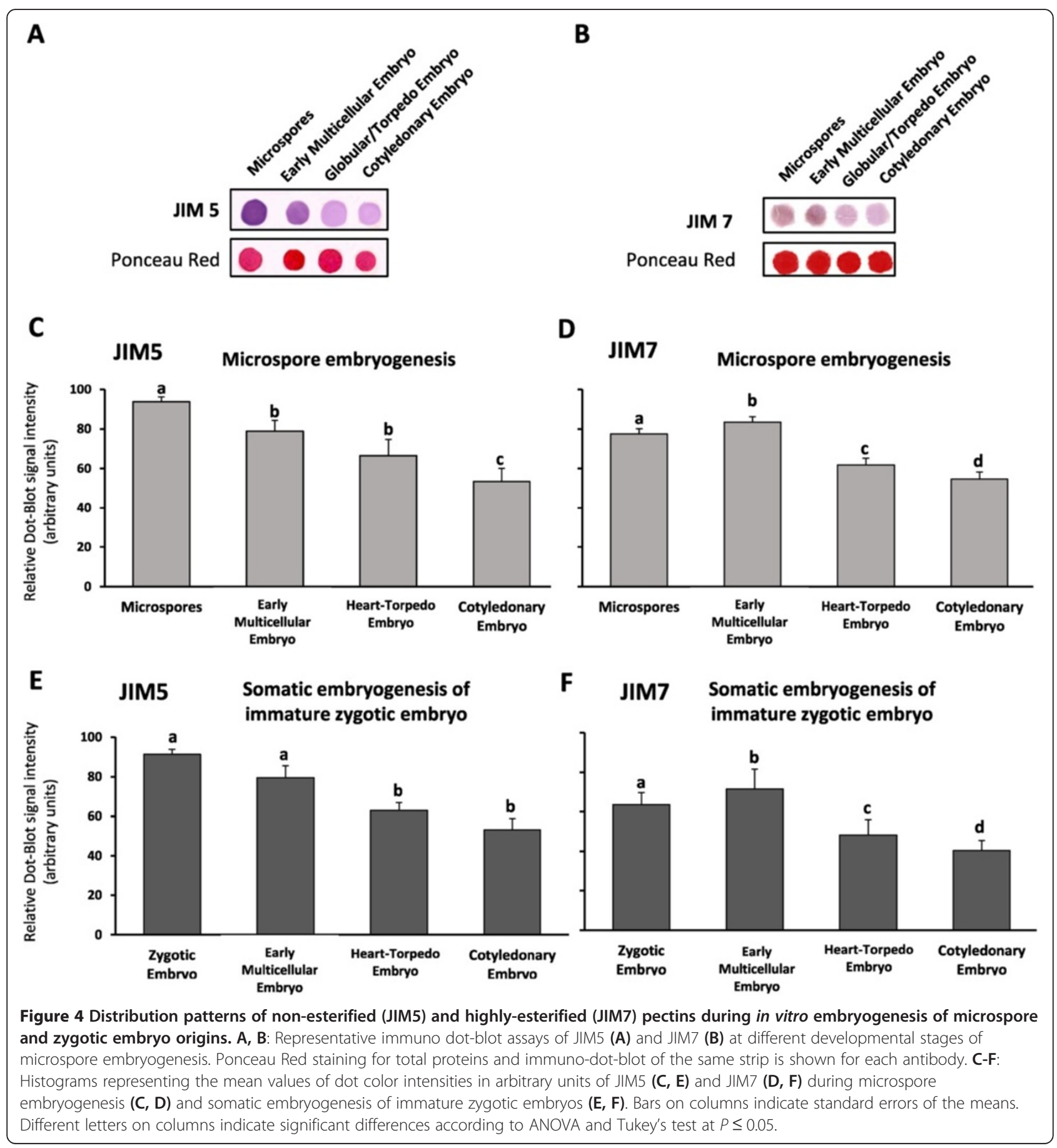


highly-esterified (JIM7 labelling) pectins. JIM7 labelling was intense on peripheral and inner cell walls of early multicellular embryos ("emb" in Figure 5A, A', B, B'). In contrast, early multicellular embryos showed very low or no labeling with JIM5 antibody on inner cell walls, only the peripheral wall layer surrounding the multicellular embryos exhibited JIM5 labelling (Figure 5E, E, F, F'). At more advanced developmental stages, globular embryos developed by direct and secondary embryogenesis showed very low or no labeling with JIM7 or JIM5 antibodies, whereas cell walls of embryogenic masses appeared labeled with both antibodies ("ms" in Figure 5C, C', D, D, H, $\left.\mathrm{H}^{\prime}\right)$. The fact that the results of the dot-blot assays showed faint positive JIM5 and JIM7 signals on advanced embryo stages indicated a higher sensitivity of this assay in comparison with immunofluorescence on resin sections where only epitopes exposed on the section surface can be detected; on the other hand, the possibility that some cells of the embryogenic masses would remain attached to embryos in the samples used for dot-blot assays and slightly contribute to dot-blot signals, cannot be completely excluded.

\section{Localization of endogenous auxin during early embryogenesis of both microspore and zygotic embryo origins}

The localization of the endogenous auxin indol acetic acid, IAA, was approached by immunofluorescence assays using specific anti-IAA antibodies. Results showed similar patterns of IAA localization in the two embryogenesis pathways, from microspores and from zygotic embryos. After embryogenesis induction, very low or no IAA labeling was observed in microspores (Figure 6A, D) and immature zygotic embryos ("zye" in Figure 6G, J) in culture. In microspores, the special pollen wall, the exine, showed unspecific autofluorescence (Figure 6D). However, an intense IAA labeling was found in the cytoplasm of cells of early multicellular embryos produced in the two pathways by primary embryogenesis ("emb" in Figure 6B, E, H, K) B, F). During early secondary embryogenesis, at the surface of the embryogenic masses ("ms" in Figure 6C, F, I, L) the dense cells which originate new multicellular embryos, also showed intense IAA labeling (arrows in Figure 6C, F, I, L), whereas the subjacent embryogenic mass cells ("ms" in Figure 6C, F, I, L) did not show any labeling. Controls by immunodepletion of the IAA antibody did not show labeling in any cellular structure and developmental stage, supporting the specificity of the immunofluorescence results.

To assess the involvement of endogenous auxin accumulations in the early stages of embryogenesis of the two pathways, treatments with the inhibitor of the polar auxin transport 1-N-naphthylphthalamic acid (NPA) were performed to in vitro cultures with embryogenic masses originated from the two systems. Results were similar in embryogenic cultures of both origins microspore and immature zygotic embryos; they showed that NPA treatment affected embryo development in comparison with control cultures (Figure 7). After 20 days of NPA treatment, neither new embryos nor development of the embryogenic masses were observed on treated cultures, whereas in parallel embryogenic cultures without NPA embryogenesis normally initiated and progressed. New embryos emerging from the embryogenic masses and development of previous embryos were observed at the same time period (Figure 7).

\section{Distribution patterns of the cellular markers used (methylated DNA, highly-esterified and non-esterified pectins, and auxin) in other developmental systems with proliferating and differentiated cells}

In order to evaluate the patterns of the selected cellular features $(5 \mathrm{mdC}$, highly-esterified and non-esterified pectins, and IAA) as early markers of embryogenesis, their distribution was analyzed in other two plant developmental systems with proliferating and differentiated cells, taken as positive and negative controls. One system was the proliferating cells of developing zygotic embryos in which the markers should be found, and in a different plant species, Brassica napus, to additionally evaluate whether those features were also present in other species. The other system was a non-embryogenic system with differentiated cells, the epidermis and subjacent cell layers of mature anthers, differentiated tissues where the markers should not be present.

The results of the comparative analysis between the two systems, proliferating embryo cells and non-embryogenic differentiated cells are shown in Figure 8. In proliferating cells of the zygotic torpedo embryos (Figure 8A), the patterns of immunolocalization observed with all antibodies were similar than the patterns found in early multicellular embryos developed in vitro. Methylated DNA, localized by anti-5mdC immunofluorescence, was scarce and distributed in small spots over nuclei (Figure 8B). JIM5 and JIM7 antibodies revealing non-esterified and highly-esterified pectins respectively, exhibited localization patterns in which the walls of proliferating embryo cells appeared higher labeled with JIM7 than with JIM5 (Figure 8C, D) indicating a higher proportion of esterified pectins in these cells. Auxine immunofluorescence signal was intense in the cytoplasm of the proliferating embryo cells (Figure 8E) localized at the developing cotyledon tips of the torpedo embryo. On the contrary, the patterns of localization in the differentiated tissue of the anther wall (Figure $8 \mathrm{~F}$ ) were opposite to those found in embryo cells. $5 \mathrm{mdC}$ signal was intense and covered the whole nuclear area (Figure 8G), corresponding to abundant hypermethylated DNA. The cell walls of the anther tissues showed intense JIM5 signal and very low JIM7 


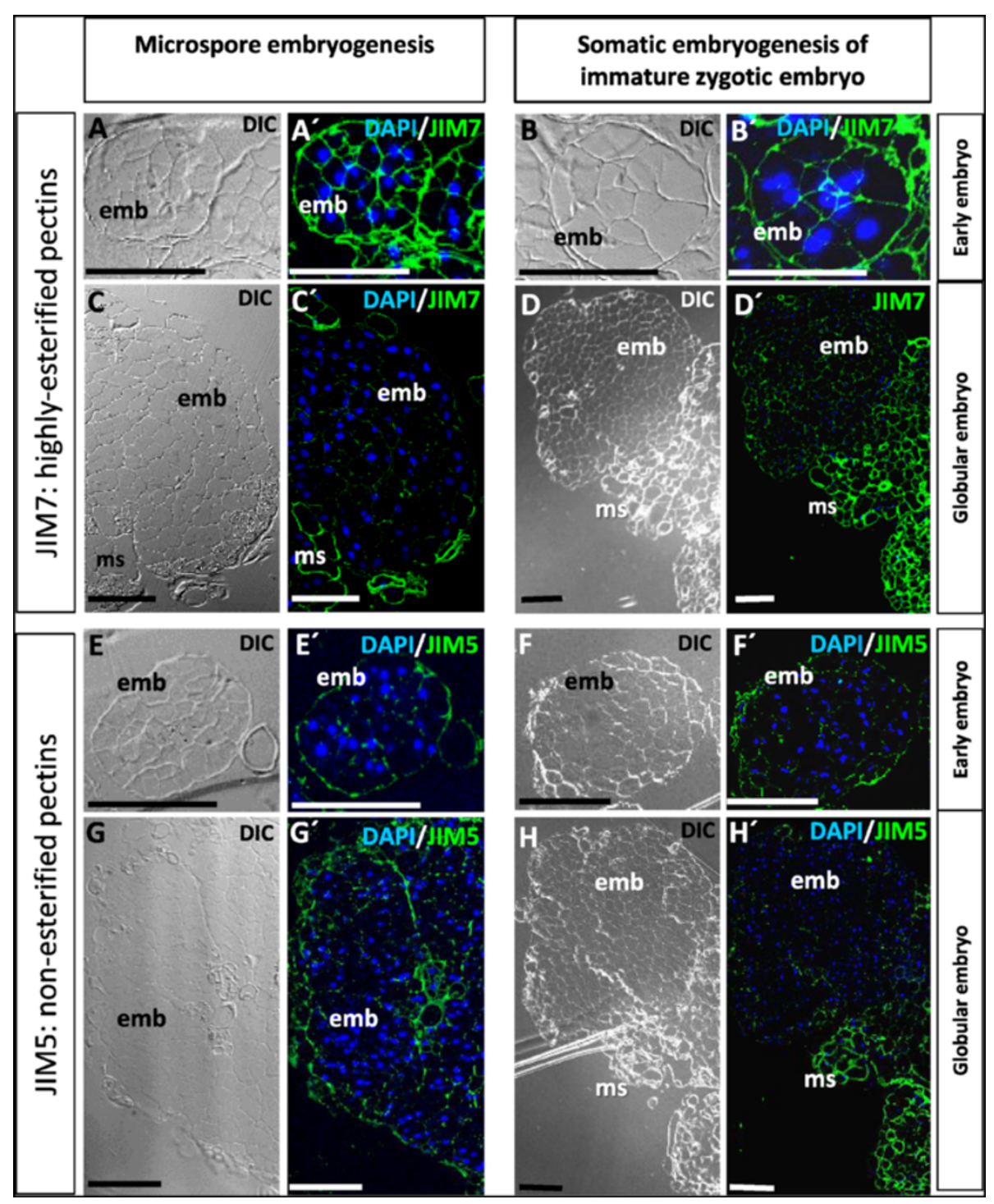

Figure 5 Immunolocalization of non-esterified (JIM5) and highly-esterified (JIM7) pectins at early in vitro embryogenesis of microspore and immature zygotic embryos. A, A', C, C', E, E', G, G': Microspore embryogenesis. B, B', D, D', F, F', H, H': Somatic embryogenesis of immature zygotic embryos. $\mathbf{A}^{\prime}-\mathbf{H}^{\prime}$ : Confocal merged images of immunofluorescence signal (green) of JIM7 $\left(\mathbf{A}^{\prime}-\mathbf{D}^{\prime}\right)$ or JIM5 $\left(\mathbf{E}^{\prime}-\mathbf{H}^{\prime}\right)$ combined with DAPI staining of nuclei (blue). A-H: Differential interference contrast, DIC, images of the same sections. A, A', B, B', E, E', F, F': Early multicellular embryos. C, $\mathbf{C}^{\prime}, \mathbf{D}, \mathbf{D}^{\prime}, \mathbf{G}, \mathbf{G}^{\prime}, \mathbf{H}, \mathbf{H}^{\prime}$ : Large multicellular and globular embryos (emb) emerging from embryogenic masses (ms) by secondary embryogenesis. Bars: $100 \mu \mathrm{m}$.

signal which indicated a higher proportion of non-esterified pectins in these cell walls. Very low or no IAA signal was observed in differentiated cells of the anther wall layers (Figure 8J).

\section{Discussion}

Global DNA methylation decrease accompanies nuclear remodeling in early embryo cells

DNA methylation plays an essential role in plant growth as a mechanism to epigenetically maintain developmental fates in proliferating and differentiating cells $[14,15,32-34]$. In the present work, DNA methylation level and distribution pattern, in relation to chromatin changes, have been analyzed during early embryogenesis of the two pathways, of microspores and zygotic embryos, results suggesting that the initiation of both embryogenic processes is epigenetically regulated. Differences in global DNA methylation levels and changes in the 5-methyl-deoxy-cytidine (5mdC) distribution patterns were found in the early embryo cells of the two in vitro embryogenesis pathways analyzed, suggesting changes of nuclear activity. A significant decrease in global DNA methylation was observed in early multicellular embryos in comparison with microspores, 


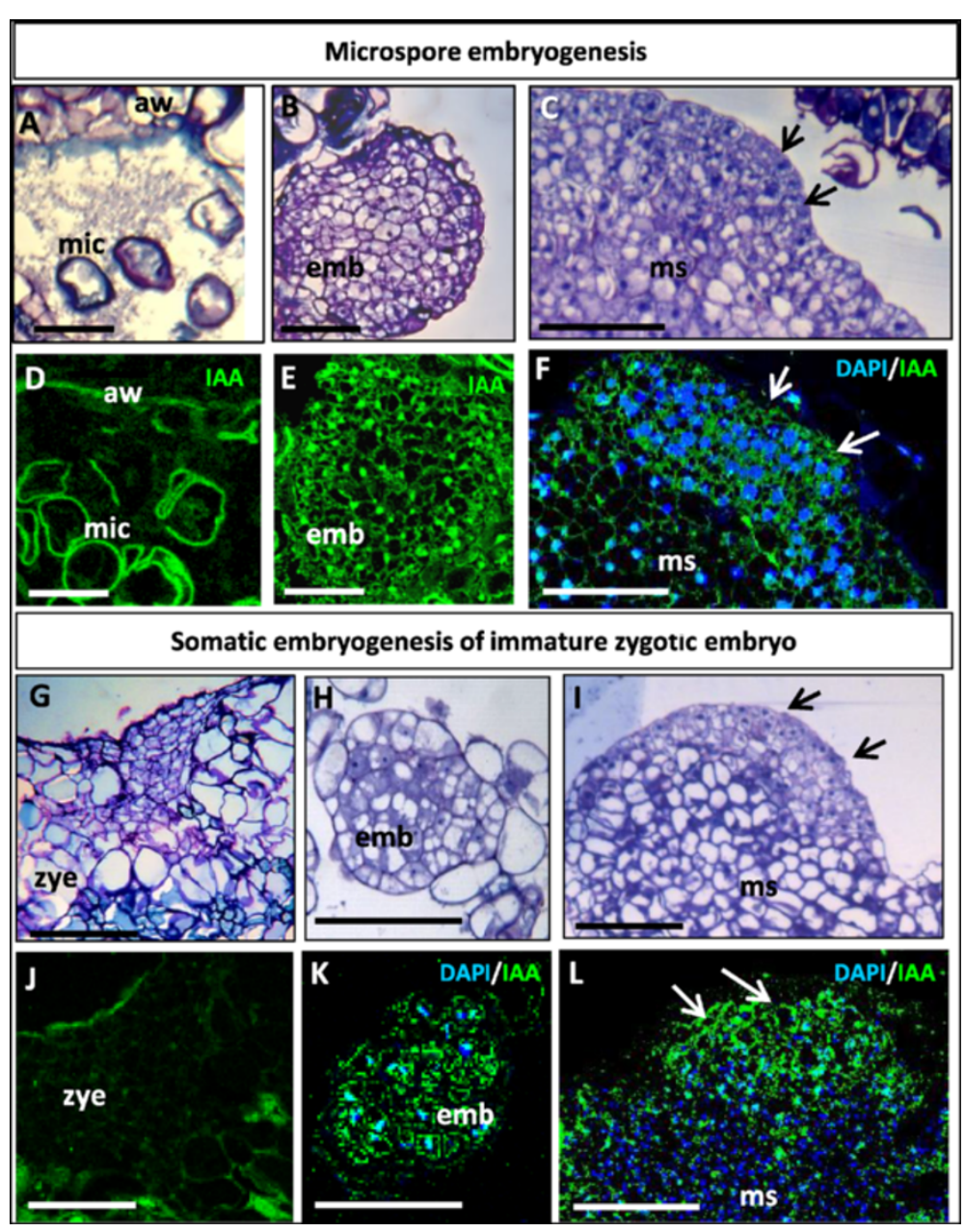

Figure 6 Immunolocalization of auxin (IAA) at early in vitro embryogenesis of microspore and immature zygotic embryos. A-F: Microspore embryogenesis. G-L: Somatic embryogenesis of immature zygotic embryos. A, B, C, G, H, I: Resin sections stained by toluidine blue. D, E, F, J, K, L: Confocal images of IAA immunofluorescence signal (green); in some images, DAPI staining of nuclei (blue) is also shown merged with the green IAA signal (F, K, L).A, D: Microspores (mic). B, E, H, K: Early multicellular embryos (emb). C, F, I, L: Dense cells (arrows) from which early embryos originate at the surface of embryogenic masses (ms). Bars A, D: $50 \mu \mathrm{m} ; \mathbf{B}, \mathbf{C}, \mathbf{E}-\mathbf{L}: 100 \mu \mathrm{m}$.

immature zygotic embryos or embryogenic mass cells from both embryogenesis in vitro systems. Reports in tree species showed that the morphogenic capacity was associated with low levels of DNA methylation [32] and a transient DNA demethylation of the ovules occurred after pollination [35]. In Brassica napus, a decrease of DNA methylation has been also reported at early stages of microspore embryogenesis [14].

The immunolocalization essays showed not only a decrease on the $5 \mathrm{mdC}$ labelling in the cells of early embryos derived from microspores and zygotic embryos, but also a change in the distribution pattern of $5 \mathrm{mdC}$ in small nuclear spots, in contrast with the $5 \mathrm{mdC}$ distribution pattern over large nuclear regions corresponding with highly condensed chromatin masses of non-embryo cells. This $5 \mathrm{mdC}$ distribution pattern over small heterochromatin masses correlates with the pattern found in active proliferating cells of root meristems [34], and early microspore-derived embryos of rapeseed, Brassica napus, with high transcriptional activity and decondensed chromatin patterns $[11,14]$. In contrast, $5 \mathrm{mdC}$ distribution over large heterochromatin masses has been associated with decreased cellular activity stages and cell differentiation, as in the generative/sperm cells of pollen grains, in the differentiating cells of advanced embryos $[14,15]$ or in the tapetal cells during the high chromatin condensation occurring during their developmental programmed cell death [36].

The data presented here revealed an epigenetic change associated with the switch towards the embryogenic developmental program and with the activation of cell proliferation occurring at the beginning of embryogenesis in the two pathways studied, microspore embryogenesis through anther culture and somatic embryogenesis from 

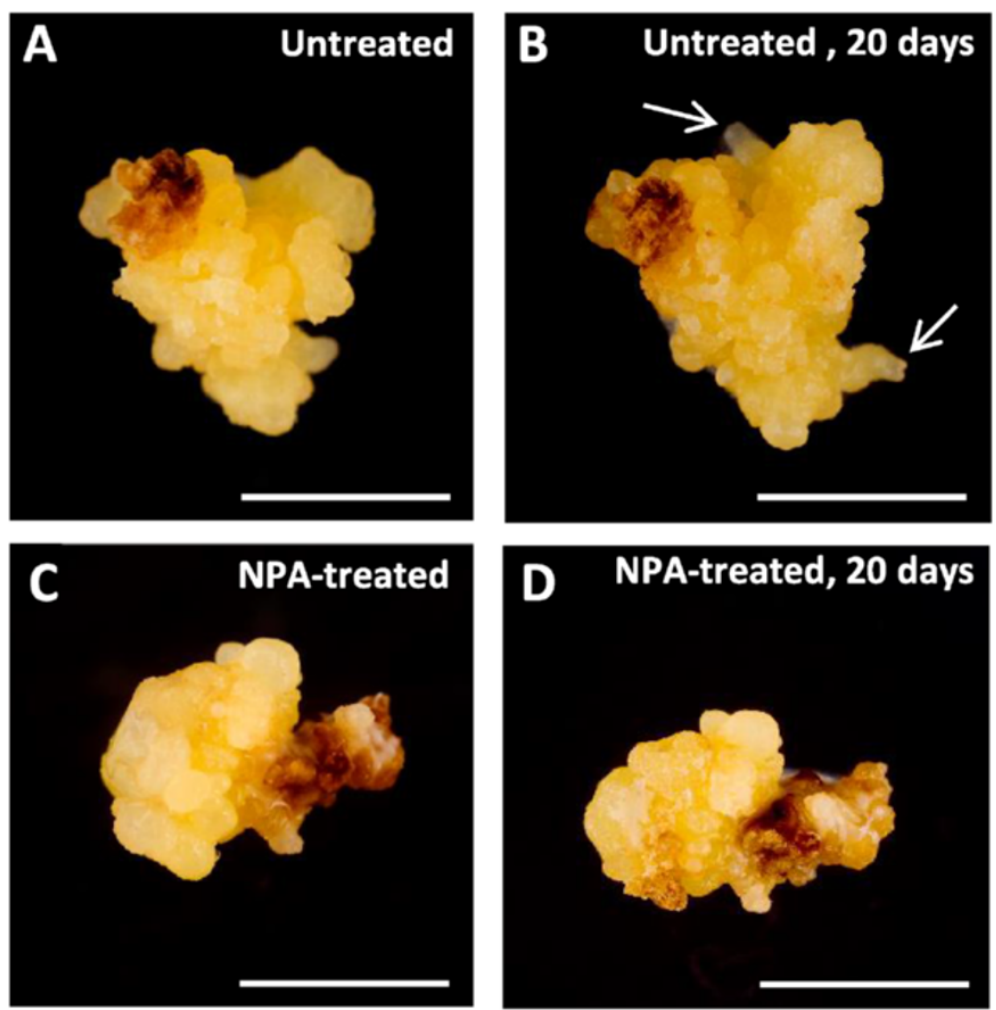

Figure 7 Effects of inhibiting auxin transport by NPA on in vitro embryogenesis initiation and progression. Embryogenic masses originated by secondary embryogenesis from immature zygotic embryos. A, B: Control cultures, without NPA, at the beginning of the treatment (A) and 20 days afterwards (B), when embryo development and new embryos (arrows) were observed. C, D: Culture containing $40 \mu \mathrm{M}$ NPA at the beginning of the treatment (C) and 20 days afterwards (D), no further growth or new embryos were observed. Bars $5 \mathrm{~mm}$.

immature zygotic embryos, for the first time in a woody species, cork oak.

\section{Cell walls of early embryo cells exhibit higher levels of esterified pectins}

Increasing evidence has linked the cell wall remodeling with many processes involved in plant growth and development, including somatic embryogenesis [22,37,38]. Several monoclonal antibodies have been used to unravel the involvement of specific cell wall epitopes in controlling cell growth and morphogenesis; specifically, there are different studies on antigen distribution detected by the antibodies JIM5 and JIM7 recognizing non-esterified and highly-esterified pectins respectively, in several plant tissues and organs [20,21,39]. In the present work, we have used both JIM5 and JIM7 antibodies to analyze changes in cell wall associated with in vitro embryogenesis initiation in Quercus suber $\mathrm{L}$.

In very young microspore-derived embryos of herbaceous species (Capsicum annuum and Brassica napus), a high level of esterified pectins was observed in the cell walls $[17,18,40]$. Using an in situ localization approach at both light and electron microscopy levels, it has been reported that in walls of proliferating cells, the levels of esterified pectins were higher than in the differentiating cells, which showed cell walls rich in non-esterified pectins $[17,18]$. Differences in the proportion of esterified pectins between microspores and microspore-derived embryos were reported in tree species, such as Quercus suber, Citrus clementina, and Olea europaea $[8,10,23]$.

The results presented here showed differences in the distribution pattern of highly-esterified pectins in early embryo cells in comparison with non-embryogenic cells, in the two pathways (embryogenesis of microspores and zygotic embryos) in cork oak. Highly-esterified pectins were more abundant in early embryo cell walls than in microspores, zygotic embryo and embryogenic mass cells, while they diminished with embryo development and differentiation. This evidence was consistent with the abundance of esterified pectins in the newly-formed walls of proliferating cells of young microspore-derived embryos and root tip meristematic cells of some herbaceous species $[17,18]$, thus providing experimental support indicating that a high proportion of esterified pectins in walls is not only a marker for proliferation events, but also an early marker of both reprogramming pathways to embryogenesis, of microspores and immature zygotic embryos origins. 


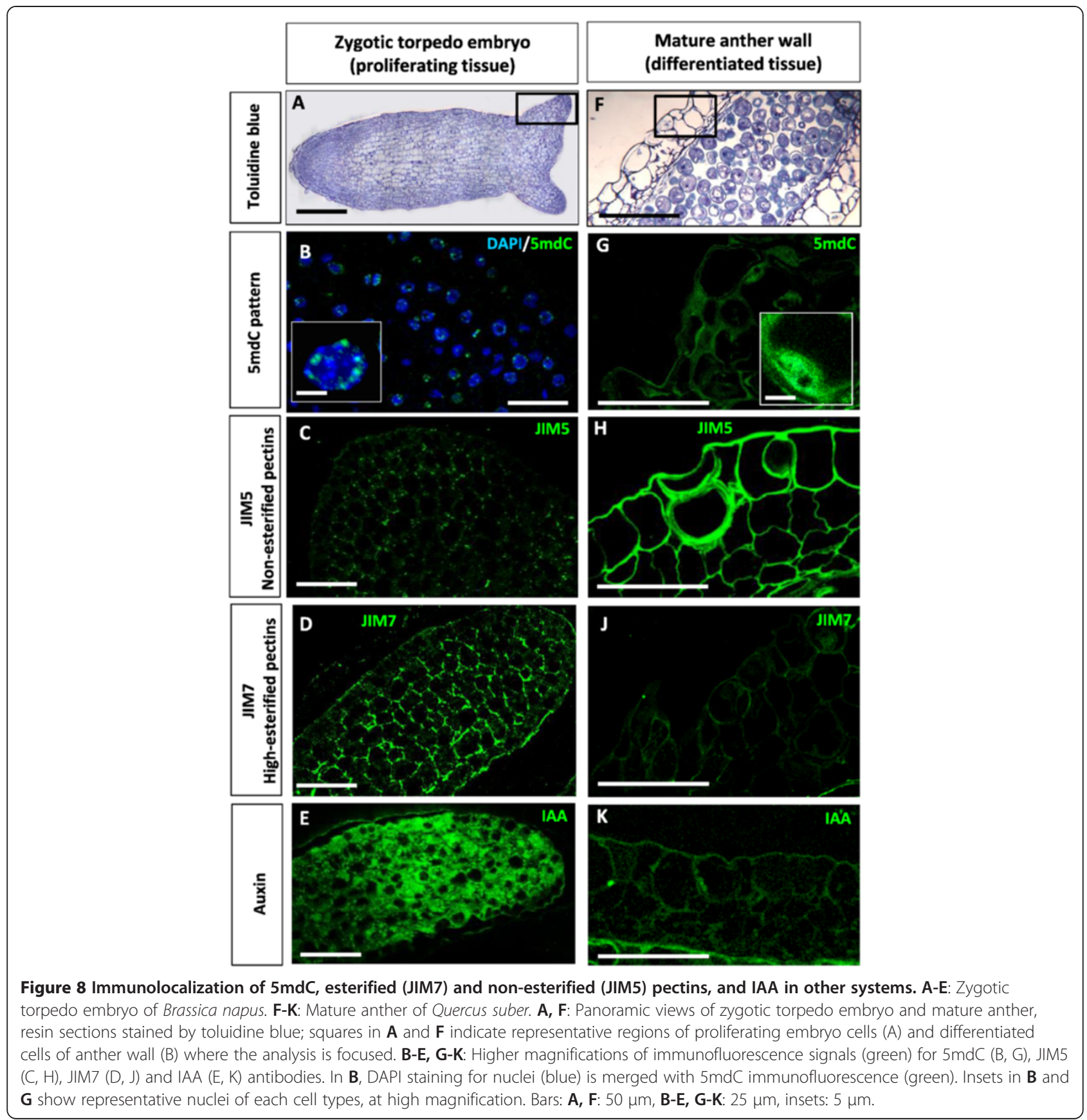

Our results showed that, in contrast with the inner cell walls, the peripheral wall layer that surrounds the early multicellular embryos was labeled by JIM5. Previous reports have described the presence of a thick wall underneath the exine, the special microspore wall, in embryogenic microspores and young embryos of various species, like Capsicum annuum and Olea europaea $[9,10]$. The development of those peripheral thick wall in early stages of somatic embryogenesis and organogenesis, and also microspore embryogenesis, has been reported as a specific feature of these processes $[9,10,16]$, though the nature of this wall has not been elucidated yet. It has been proposed that this layer could constitute an organized network with differential wall components which may create a specific cellular environment with altered permeability and receptors, providing conditions to express morphogenic competence [16]. The present study reveals that at early stages of the two Quercus suber in vitro embryogenesis pathways, from microspores and immature zygotic embryos, there is also a peripheral wall in early multicellular embryos with a differentially higher proportion of non-esterified pectins 
than the inner cell walls, providing additional evidences of the existence of special wall structures surrounding groups of cells committed for entering the cell cycle and initiate the embryogenic program.

\section{High endogenous auxin level is present in early embryo cells}

Many aspects of auxin action depend on its local biosynthesis and differential distribution within plant tissues, mainly regulated by its directional transport between cells [41]. We have analyzed the endogenous auxin IAA distribution and level during early stages in the two embryogenesis pathways, from microspore and immature zigotic embryos, in cork oak, in vitro systems in which the embryo development occurs in a medium free of exogenous IAA [42,43]. Interestingly, the IAA immunolocalization assays revealed a differential and significant increase of the IAA endogenous levels in the early multicellular embryo cells, in comparison with the microspores, immature zygotic embryos and embryogenic mass cells which showed very low IAA signal. In Arabidopsis, auxin has been localized by the expression of the auxin-responsive promoter DR5 in cells of the embryo proper at very early stages [24,44]. IAA biosynthesis is associated with rapidly dividing and rapidly growing tissues, especially in shoots and roots, free auxin concentrations in the living plant are in the apical meristems of shoots, young leaves, root meristems and lateral root initiation sites $[45,46]$. In a new Brassica napus microspore embryogenesis in vitro system at low temperature, our group reported preliminary results showing that IAA also localized in cells of early multicellular embryos [28], similarly to early zygotic embryogenesis.

The results presented here indicate the increase of endogenous levels of IAA in the formation of early multicellular embryos of both microspore and zygotic embryo origins, in Quercus suber. This result, together with the fact that the inhibition of auxin transport by NPA negatively affected embryogenesis initiation and development suggest that endogenous IAA biosynthesis and transport would be involved in the activation of proliferation and the switch of the embryogenic program of the reprogrammed microspores, zygotic embryo and embryogenic mass cells.

\section{Early embryogenesis from microspores and zygotic} embryos exhibits similar early markers: epigenetic changes by DNA hypomethylation, cell wall remodelling by high pectin esterification and high endogenous auxin levels

In vitro embryogenesis initiation and progression is conditioned by many factors, still largely unknown. The comparative analysis performed here during the early stages of embryogenesis in two different in vitro systems, microspore embryogenesis through anther cultures and somatic embryogenesis from immature zygotic embryo cultures, in a woody species, Quercus suber, has permitted the identification of differential cell features, summarized in Table 1, specific to the reprogramming process towards embryogenesis, as early markers which are similar in both embryogenesis pathways from microspore and immature zygotic embryos in cork oak. These differential features are the decrease of DNA methylation, the remodeling of cell walls by increasing the proportion of esterified pectins, and the accumulation of endogenous auxin in the cells that initiate the embryogenic program. The present work provides new evidences of two important questions for the understanding of the in vitro embryogenesis process. On one hand, the reported data reveal that several basic cellular features undergo similar changes in the two different embryogenesis pathways studied at early stages, indicating that basic cellular processes underlying early in vitro embryogenesis are common to various systems and suggesting that general mechanisms could regulate the process independently of the cell type origin and culture conditions . Moreover, the results illustrate the relevance of three cellular processes which specifically occur in early embryo cells just after induction, while the same cellular changes are not observed neither before embryogenesis initiation neither at advanced developmental stages, fact that permits to consider these features (DNA hypomethylation, cell wall

Table 1 Early markers present in in vitro embryogenesis of both microspores and immature zygotic embryos origins

\begin{tabular}{|c|c|c|}
\hline & Before embryogenesis induction & After embryogenesis induction \\
\hline Early markers & $\begin{array}{l}\text { Cells from which embryos originate (microspores, } \\
\text { immature zygotic embryos, embryogenic masses) }\end{array}$ & $\begin{array}{l}\text { Early embryos (derived from microspores, immature } \\
\text { zygotic embryos and embryogenic masses) }\end{array}$ \\
\hline DNA methylation level & High $(++)$ & $\operatorname{Low}(+/-)$ \\
\hline DNA methylation pattern & Large chromatin masses & Small chromatin masses \\
\hline $\begin{array}{l}\text { Highly-esterified pectins in } \\
\text { cell walls }\end{array}$ & Mid $(+)$ & High $(++)$ \\
\hline $\begin{array}{l}\text { Peripheral wall layer (rich in } \\
\text { non-esterified pectins) }\end{array}$ & Not present $(-)$ & Present $(+)$ \\
\hline Endogenous auxin & $\operatorname{Low}(+/-)$ & High $(++)$ \\
\hline
\end{tabular}


remodeling by high esterification of pectins, and endogenous auxin increase) as early markers of the process, opening the possibility to design strategies for efficient manipulation of in vitro protocols to improve yields.

A previous cytochemical and immunocytochemical study compared the structural organization of advanced globular embryos of both origins, microspores and immature zygotic embryos, finding similar anatomy and cellular organization patterns in both of them; the common features found concerned high vacuolization, small nuclear size and structure, abundant ribosomal population, and presence of starch granules [7]. Studies in stress-induced microspore embryogenesis and somatic embryogenesis of other species have indicated the involvement of epigenetic marks $[14,15]$, cell wall components [10,16-19] and endogenous phytohormones $[27,28,47]$ in the initiation and progression of organogenesis and embryogenesis. Some of the markers described here in cork oak have been also found in other plant species, for example, DNA hypomethylation has been observed in microspore embryos of Brassica napus [14] and Hordeum vulgare [15], a high proportion of esterified pectins in cell walls was described in microspore embryos of Capsicum annum $[17,18]$, and production of endogenous auxin in early embryos was found in microspore embryogenesis of rapeseed [28]. $\mathrm{T}$ he present work is the first report on microspore and somatic embryogenesis in a forest tree, that shows all these cellular processes during the initiation of two different embryogenesis pathways which are induced by different in vitro protocols. Interestingly, the reported cell modifications were observed not only in early embryos originated directly from microspore and zygotic embryos, but also in secondary embryos produced from embryogenic masses, at early stages. In contrast, these features were not found in the cells that originated the embryos (microspores and immature zygotic embryo cells) before embryogenesis induction. Moreover, they were also found in proliferating cells of zygotic embryos of other plant species, B. napus, whereas differentiated cells of mature organs, as revealed in mature anthers here, showed opposite features than early embryo cells regarding DNA methylation, pectin esterification and endogenous auxin content. The fact that the same differential cell features appear in the two early embryo cells of both origins, from microspores and immature zygotic embryos, produced by primary or secondary embryogenesis indicate that they can be considered as early markers of in vitro embryogenesis. As stated before, some of them have been reported individually in embryos of other plants $[14,15,17,18,28]$ and, in the present work, the three features were found on proliferating cells of zygotic embryos in a different species, Brassica napus, these data support the idea that these early markers reflect a general behavior that could be exploited for other species.

Increasing evidences have documented the effect of different phytohormones, including auxin, in signaling processes of cell wall remodeling, necessary for cell elongation and growth, and in chromatin remodeling for the activation of specific gene expression developmental programs. The changes reported here affecting epigenetic marks and cell wall polymers are associated with the accumulation of auxin in early embryo cells, this data could reflect different processes that are interconnected in complex regulatory mechanisms that control cell reprogramming and embryogenesis initiation.

\section{Conclusions}

The identification of early markers of embryogenesis can help to monitor the metabolic processes involved in the induction providing a wider understanding of the physiology and mechanisms controlling plant cell reprogramming and embryogenic competence acquisition. The present work is the first report that shows, by a comparative analysis during the early stages of embryogenesis, that various cellular processes, DNA hypomethylation, cell wall remodeling by increasing pectin esterification, and endogenous auxin increase, occur concomitantly at early stages of two embryogenesis pathways, microspore embryogenesis and embryogenesis from immature zygotic embryos, which are induced by different in vitro protocols, identifying similar early embryogenic markers in Quercus suber. The data reported here, in a woody species, which have shown to be extremely recalcitrant to in vitro embryogenesis, is of particular relevance. The information gained will be useful to increase our knowledge on the regulatory mechanisms and involved factors in the in vitro induction of embryogenesis, opening the door to identify novel strategies and selective targets for improving the efficiency of the process in biotechnology, agronomic and forestry breeding programs.

\section{Methods}

\section{Plant material}

Catkins and immature pollinated acorns were collected from Quercus suber L. trees every week during flowering period and fruit development period respectively from two selected trees in the E.T.S.I. de Montes (Universidad Politécnica de Madrid) and three selected trees from El Pardo, Madrid, Spain.

The branches bearing catkins were pre-treated by chilling in darkness with moist cotton at $4^{\circ} \mathrm{C}$ for 1 week. Catkins of different sizes were squashed and stained with DAPI (4, 6-diamidino-2-phenylindole) to visualize the nuclei and observed under fluorescence microscope to determine the developmental stage of the microspore. The selected catkins, only those red coloured and 1.5- 
$2.5 \mathrm{~cm}$ long that contains the vacuolated microspore, the most responsive stage for embryogenesis induction [48], were surface sterilized. Immature acorns selected at the appropriate developmental stage for somatic embryogenesis induction were those with small size, $1 \mathrm{~cm}$, and green colour; they were kept at $4^{\circ} \mathrm{C}$ for one week. Catkins and acorns were surface sterilized by immersion in $70 \%$ ethanol (Merck), for $1 \mathrm{~min}$, and 2\% sodium hypochlorite with a drop of Tween-20 for 20 min followed by three rinses in sterile distilled water for $10 \mathrm{~min}$ each. The anthers and the immature zygotic embryos were carefully excised from catkins and acorns respectively, isolated, dissected and cultured under aseptic conditions in a laminar flow cabinet.

For their use as controls in other plant systems, some mature anthers of Quercus suber were extracted directly from catkins, without any pretreatment, and fixed and processed for further use in immunofluorescence assays. Also, zygotic embryos at the torpedo stage were extracted from siliques of Brassica napus plants, fixed and processed for immunofluorescence.

\section{Culture media}

Basal culture medium for both microspore and somatic embryogenesis contained full macronutrients [49], micronutrients and cofactors [50], 3\% sucrose and was solidified with $0.8 \%$ Agar, adjusted to $\mathrm{pH}=5.6$, and autoclaved. The amino acids and labile compounds were added after autoclaving by filter-sterilization $(0.22 \mu \mathrm{m})$. Microspore embryogenesis induction medium was basal culture medium supplemented with $1 \%$ active charcoal, while somatic embryogenesis induction medium was supplemented with $0.5 \mathrm{mg} / \mathrm{L} 2,4-\mathrm{D}$.

\section{In vitro embryogenesis of microspores and immature zygotic embryos}

Anthers containing vacuolated microspores were isolated from the catkins and plated in Petri dishes with induction medium for microspore embryogenesis in an amount of 100 anthers per plate approximately, subjected at $32^{\circ} \mathrm{C}$ in darkness during 5 days [43], and then transferred to $25^{\circ} \mathrm{C}$. After one month visible embryos emerged from inside the anther. Embryos obtained were isolated and transferred to plates containing basal medium without active charcoal and supplemented with $0.5 \mathrm{~g} / \mathrm{L}$ glutamine, where the embryos were propagated by secondary embryogenesis.

Immature zygotic embryos were cultured in Petri dishes containing induction media for somatic embryogenesis placing 5 embryos per plate and cultured at $25^{\circ} \mathrm{C}$ with $16 / 8 \mathrm{~h}$ light/darkness, for one month $[42,51]$. Then, the immature zygotic embryos were transferred to growth regulator-free medium, where new embryos and embryogenic masses, were found and suffered recurrent somatic embryogenesis process.
Every week, embryogenesis cultures, were observed under a microscope Leica MZ16FA, to monitor the embryogenesis process. Culture samples at different developmental stages of the two embryogenic systems were either fixed for microscopic analysis or frozen by immersion in liquid nitrogen for biochemical assays.

\section{Treatments with NPA}

$N$-1-Naphthylphthalamidic acid, NPA (Duchefa), auxin transport inhibitor, was added at $40 \mu \mathrm{M}$ concentration to the corresponding media of microspore and somatic embryogenesis, using a stock of 0.1 M NPA in DMSO, after filtering with a sterile Ministart filter (Sartorius Biotech). The NPA was added to plates of propagating embryogenic masses by secondary embryogenesis, using parallel plates of the same cultures and keeping some plates lacking NPA as controls. To asses NPA effects on embryogenesis development, the embryo growth and emergency of new embryos per plate was evaluated after 20 days in NPA-treated and control cultures.

\section{Antibodies}

The following antibodies and dilutions were used: anti-5methyl-deoxy-cytidine $(5 \mathrm{mdC})$ mouse monoclonal diluted 1:100 (Eurogentec, Cat. N: BI-MECY-0100, Liege, Belgium), anti-IAA mouse monoclonal diluted 1:100 (Sigma, Cat. N: A 0855), JIM5 rat monoclonal (Plant Probes, Cat. N: JIM5), and JIM7 rat monoclonal (Plant Probes, Cat N: JIM7) diluted 1:25 for immunofluorescence, and 1:100 for immunodot-blot assays.

\section{Fixation and processing for immunofluorescence}

Embryogenesis culture samples from microspores and immature zygotic embryos were collected at different times and fixed overnight with $4 \%$ paraformaldehyde in phosphate buffered saline (PBS) at $4^{\circ} \mathrm{C}$. For control experiments, mature anthers of Quercus suber and zygotic torpedo embryos of Brassica napus were excised from plants and fixed by the same procedure. Most samples were embedded in resins and some large samples were processed for cryostat.

\section{Processing for cryostat sectioning}

Fixed samples were washed in PBS, cryoprotected through a gradual infiltration in sucrose solutions: $0.1 \mathrm{M}, 0.5 \mathrm{M}$, $1 \mathrm{M}, 1.5 \mathrm{M}$ and $2 \mathrm{M}$ for $1 \mathrm{~h}$ each and $2.3 \mathrm{M}$ overnight, at $4^{\circ} \mathrm{C}$, embedded in Tissue-Tek optimal cutting temperature (OCT) compound and frozen on dry ice for sectioning in the cryostat (Leica CM 1950). 20-30 $\mu$ m thick sections were collected on glass slides, washed with water to eliminate the OCT and transferred to a water drop over 3-aminopropyl-triethoxy-silane (APTES)-coated slides, air-dried and stored at $-20^{\circ} \mathrm{C}$ until use for immunofluorescence (IF). 


\section{Processing for resin embedding and ultramicrotome sectioning}

Fixed samples were washed in PBS, dehydrated through an acetone series (30\%, 50\%, 70\%, 90\% and 100\%) and embedded in Technovit 8100 resin (Kulzer, Germany) at $4^{\circ} \mathrm{C}$. The blocks were sectioned at 1-2 $\mu \mathrm{m}$ thickness and stained with $1 \%$ toluidine blue for structural analysis, mounted with Eukitt and observed under bright field microscopy. Some sections were placed on APTES coated slides, air-dried, and stored at $4^{\circ} \mathrm{C}$ until use for immunofluorescence.

\section{Immunofluorescence}

Immunofluorescence (IF) was performed essentially as previously described by us $[14,19,28]$. For cryostat sections, permeabilization was required prior to IF. After thawing the sections at room temperature, they were dehydrated and rehydrated in a methanol series (30\%, 50\%, 70\%, 90\%, 100\%, 90\%, 70\%, 50\%, 30\%, 5 min each) and PBS. They were subsequently subjected to enzymatic digestion of cell walls for additional permeabilization by treatment with an enzymatic mixture $(2.5 \%$ pectinase, $2.5 \%$ cellulase and $2.5 \%$ pectoliase) in PBS for $45 \mathrm{~min}$. Semithin resin sections did not required permeabilization and were subjected directly to the immunodetection, after incubation in PBS for a few minutes. At this step, all section types followed the same protocol of IF. Sections were first blocked with 5\% Bovine Serum Albumin (BSA) or $10 \%$ foetal calf serum (FCS) for IAA-immunofluorescence, in PBS for $10 \mathrm{~min}$, and incubated for $1 \mathrm{~h}$ with JIM5, JIM7, anti-5-methyl-deoxy-cytidine (5mdC), anti-IAA, rat and mouse monoclonal antibodies respectively. For the $5 \mathrm{mdC}$ antibody the sections were previously denaturated with $2 \mathrm{~N} \mathrm{HCl}$ for $45 \mathrm{~min}$. After three rinsing steps in PBS, sections were incubated for 45 min with Alexa Fluor 488labelled anti-rat or anti-mouse IgG antibody diluted 1:25 in BSA $1 \%$ in the dark. After washing in PBS, nuclei were stained with DAPI, washed with PBS, mounted in Mowiol and examined in a confocal microscope (Leica TCS-SP2AOBS, Vienna, Austria). Optical sections and maximum projections images were obtained with software running in conjunction with the confocal microscope (Leica software LCS version 2.5).

Negative controls were performed as follows: for the $5 \mathrm{mdC}$ antibody by avoiding the denaturation step; and for the IAA antibody by immunodeplection assays; the antiIAA antibody was incubated with a solution of $5 \mathrm{mg} / \mathrm{ml}$ synthetic IAA $(1: 4, \mathrm{v} / \mathrm{v})$ at $4^{\circ} \mathrm{C}$ overnight. The pre-blocked antibody solution as used as primary antibodies for immunofluorescence, following the same protocol and conditions described above.

\section{Immuno dot-blot assay for JIM5 and JIM7 antibodies}

Samples from the two embryogenesis cultures were collected at different developmental stages, and frozen in liquid nitrogen. Dot-blot assays for JIM5 and JIM7 antibodies were performed as described by us [19]. Samples, $0.1 \mathrm{~g}$ for each sample, were homogenized in liquid nitrogen using a chilled mortar and pestle, with $50 \mathrm{ml}$ of buffer containing $50 \mathrm{mM}$ Tris- $\mathrm{HCl} \mathrm{pH} 7.2,50 \mathrm{mM}$ trans-1,2diaminocyclohexane-N,N,-tetra-acetic acid (CDTA) and $25 \mathrm{mM}$ dithiothreitol. The resulting supernatant concentrations were determined according to Bradford (Bio-Rad Protein Assay reagent) using bovine serum albumin (BSA) as calibrator and all samples were adjusted to a concentration of $0.5 \mathrm{mg} / \mathrm{ml}$. For immuno Dot-Blot assays, $5 \mu \mathrm{l}$ aliquots of adjusted supernatants were applied to a nitrocellulose membrane (Millipore; Bedford, MA, United Kingdom) and left to dry for $1 \mathrm{~h}$. Strips were first stained for total protein detection with Ponceau red, and the images of the stained dots were captured by scanning. The membrane was incubated overnight at room temperature, with the primary antibodies (JIM5 and JIM7) diluted 1:100, in the blocking buffer ( $2 \%$ powdered skimmed milk containing $0.05 \%$ Tween-20 in PBS), washed, and incubated for $1 \mathrm{~h}$ with alkaline phosphatase-conjugated antirat antibody diluted 1:1.000 in the blocking solution. Finally, the epitopes recognized by the antibodies were revealed by treatment with a nitroblue tetrazolium, bromochloroind-olyl-phosphate (NBT-BCIP) mixture. Quantification of the relative intensity of the dot blot signals was performed by using the tool for color intensity quantification of the image analysis software Adobe Photoshop. For the quantification, images of three replicates for each antibody, developmental stage and embryogenesis pathway were used. Values of color intensity, in arbitrary units, for each antibody were calculated and adjusted to the intensity of Ponceau S dots, which estimate the protein level. Mean values and standard deviations were calculated and the results showed in histograms. Differences among stages were tested by one-way ANOVA analysis of variance followed by Tukey's multiple comparison test at $P \leq 0.05$.

\section{Quantification of DNA methylation by $5 \mathrm{mdC}$ ELISA-based immunoassay}

Samples were collected from both embryogenesis culture systems, from microspores and immature zygotic embryos, at different developmental stages and frozen in liquid nitrogen. Quantification of DNA methylation was performed as previously described [34]. Total DNA was extracted of each sample from $0.1 \mathrm{~g}$ of frozen material, using a plant genomic DNA extraction kit (DNeasy Plant Mini, Qiagen) following the kit's instructions. The purified DNA, $100 \mathrm{ng}$ of genomic DNA for each sample, was used for global DNA methylation quantification by using a MethylFlash Methylated DNA Quantification Kit (Colorimetric, Epigentek, NY) added to an ELISA plate where the methylated fraction of DNA was quantified 
using 5-deoxy-methyl-cytidine specific antibodies. The amount of methylated DNA was proportional to the optical density (OD) measured in an ELISA plate reader at $450 \mathrm{~nm}$. By subtracting negative control readings from the readings for the sample and the standard, the value of 5-methyl-deoxy-cytosine for each sample was calculated as a ratio of sample OD relative to the standard OD. Results were expressed as the percentage of methylated deoxy-methyl-cytosines $(5 \mathrm{mdC})$ of total DNA. For the quantification, three replicates for each developmental stage and embryogenesis pathway were used. Mean values and standard deviations were calculated and the results showed in histograms. Differences among stages were tested by one-way ANOVA analysis of variance followed by Tukey's multiple comparison test at $P \leq 0.05$.

\section{Competing interests}

The authors declare that they have no competing interests.

\section{Authors' contributions}

HRS performed most of the experimental work, in vitro cultures, immunofluorescence assays, dot-blot and ELISA-based experiments, the quantification of signals and statistics. JAM contributed to the selection of tree samples, in vitro cultures procedure and monitoring, and participated in the discussion of the results. MTS performed immunolocalization assays in zygotic embryos of Brassica napus. AGG and BP contributed to the in vitro assays and participated in the discussion of the results. MCR participated in the design of the work and in the discussion of the results. PST designed and coordinated the experimental work, analyzed the results, elaborated the conclusions and wrote the manuscript. All authors read and approved the final manuscript.

\section{Acknowledgements}

Work supported by Spanish Ministry of Economy and Competitivity (MINECO) project BFU2011-23752 and Spanish National Research Council (CSIC) project PIE 201020E038. HRS is recipient of a FPI predoctoral fellowship of MINECO (BES-2009-014245). We acknowledge support of the publication fee by the CSIC Open Access Publication Support Initiative through its Unit of Information Resources for Research (URICI).

\section{Author details}

${ }^{1}$ Pollen Biotechnology of Crop Plants group, Biological Research Center, CIB-CSIC, Ramiro de Maeztu 9, 28040 Madrid, Spain. ${ }^{2}$ ETSI Montes, Technical University of Madrid, UPM, Ciudad Universitaria, 28040 Madrid, Spain. ${ }^{3}$ Department of Plant Physiology, Faculty of Biology, Complutense University of Madrid, UCM, Ciudad Universitaria, 28040 Madrid, Spain.

Received: 16 May 2014 Accepted: 11 August 2014

Published: 21 August 2014

\section{References}

1. Vieitez AM, Corredoira E, Ballester A, Muñoz F, Durán J, Ibarra M: In vitro regeneration of the important North American oak species Quercus alba, Quercus bicolor and Quercus rubra. PCTOC 2009, 98:135-145.

2. Corredoira E, Toribio M, Vietez AM: Clonal Propagation via Somatic Embryogenesis in Quercus spp. In Tree Biotechnology. Edited by Ramawat KG, Mérillon JM, Ahuja MR. Boca Raton, Florida, USA: CRC Press; 2014:262-302.

3. Corredoira E, San-José MC, Vietez AM: Induction of somatic embryogenesis from different explants of shoot cultures derived from young Quercus alba trees. Trees 2012, 26:881-891.

4. Testillano PS, Coronado MJ, Seguí-Simarro JM, Domenech J, GonzálezMelendi P, Raska I, Risueño MC: Defined nuclear changes accompany the reprogramming of the microspore to embryogenesis. J Struct Biol 2000, 129:223-232.
5. Testillano PS, Ramírez C, Domenech J, Coronado MJ, Vergne P, Matthys-Rochon E, Risueño MC: Young microspore-derived maize embryos show two domains with defined features also present in zygotic embryogenesis. Int J Dev Biol 2002, 46:1035-1047.

6. Testillano PS, González-Melendi P, Coronado MJ, Seguí JM, Moreno-Risueño MA, Risueño MC: Differentiating plant cells switched to proliferation remodel the functional organization of nuclear domains. Cytogenet Genome Res 2005, 109:166-174.

7. Bueno MA, Gómez A, Sepulveda F, Segui JM, Testillano PS, Manzanera JA, Risueño MC: Microspore-derived embryos from Quercus suber anthers mimic zygotic embryos and maintain haploidy in long term anther culture. J Plant Physiol 2003, 160:953-960.

8. Ramírez C, Testillano PS, Pintos B, Moreno-Risueño MA, Bueno MA, Risueño MC: Changes in pectins and MAPKs related to cell development during early microspore embryogenesis in Quercus suber L. Eur J Cell Biol 2004, 83:213-225

9. Bárány I, González-Melendi P, Fadón B, Mityko J, Risueño MC, Testillano PS. Microspore-derived embryogenesis in pepper (Capsicum annuum L.): subcellular rearrangements through development. Biol Cell 2005, 97:709-722.

10. Solís MT, Pintos B, Prado MJ, Bueno MA, Raska I, Risueño MC, Testillano PS: Early markers of in vitro microspore reprogramming to embryogenesis in olive (Olea europaea L.). Plant Sci 2008, 174:597-605.

11. Seguí-Simarro JM, Corral-Martínez P, Corredor E, Raska I, Testillano PS, Risueño MC: A change of developmental program induces the remodeling of the interchromatin domain during microspore embryogenesis in Brassica napus L. J Plant Physiol 2011, 168:746-757.

12. Costa S, Shaw P: Open minded cells: how cells can change fate. Trends Cell Biol 2007, 17:101-106.

13. Arnholdt-Schmitt B: Stress-induced cell reprogramming. A role for global genome regulation? Plant Physiol 2004, 136:2579-2586.

14. Solís MT, Rodríguez-Serrano M, Meijón M, Cañal MJ, Cifuentes A, Risueño MC, Testillano PS: DNA methylation dynamics and MET1a-like gene expression changes during stress-induced pollen reprogramming to embryogenesis. J Exp Bot 2012, 63:6431-6444.

15. El-Tantawy AA, Solís MT, Risueño MC, Testillano PS: Changes in DNA methylation levels and nuclear distribution patterns after microspore reprogramming to embryogenesis in barley. Cytogenet Genome Res 2014, 143:200-208, doi:10.1159/000365232.

16. Fortes AM, Testillano PS, Risueño MC, Pais MS: Studies on callose and cutin during the expression of competence and determination for organogenic nodule formation from internodes of Humulus lupulus var Nugget. Physiol Plantarum 2002, 116:113-120.

17. Bárány I, Fadón B, Risueño MC, Testillano PS: Cell wall components and pectin esterification levels as markers of proliferation and differentiation events during pollen development and pollen embryogenesis in Capsicum annuum L. J Exp Bot 2010, 61:1159-1175.

18. Bárány I, Fadón B, Risueño MC, Testillano PS: Microspore reprogramming to embryogenesis induces changes in cell wall and starch accumulation dynamics associated with proliferation and differentiation events. Plant Signal Behav 2010, 5:341-345.

19. El-Tantawy AA, Solís MT, Costa M, Coimbra S, Risueño MC, Testillano PS: Arabinogalactan protein profiles and distribution patterns during microspore embryogenesis and pollen development in Brassica napus. Plant Reproduction 2013, 26:231-243.

20. Goldberg R, Morvan C, Roland JC: Composition, properties and localization of pectins in young and mature cells of the Mung Bean hypocotyl. Plant Cell Physiol 1986, 27:417-429.

21. Dolan L, Linstead P, Roberts K: Developmental regulation of pectic polysaccharides in the root meristem of Arabidopsis. J Exp Bot 1997 48:713-720.

22. Guillemin F, Guillon F, Bonnin E, Devaux MF, Chevalier T, Knox JP, Liners F, Thibault JF: Distribution of pectic epitopes in cell walls of the sugar beet root. Planta 2005, 222:355-371.

23. Ramírez C, Chiancone B, Testillano PS, García-Fojeda B, Germaná MA, Risueño MC: First embryogenic stages of Citrus microspore-derived embryos. Acta Biol Cracov Bot 2003, 45:53-58.

24. Möller B, Weijers D: Auxin control of embryo patterning. Cold Spring Harb Perspect Biol 2009, 1:a001545.

25. Rademacher EH, Lokerse AS, Schlereth A, Llavata-Peris Cl, Bayer M, Kientz M, Freire Rios A, Borst JW, Lukowitz W, Jurgens G, Weijers D: Different auxin 
response machineries control distinct cell fates in the early plant embryo. Dev Cell 2012, 22:211-222.

26. Raghavan V: Role of 2,4-dichlorophenoxyacetic acid (2,4-D) in somatic embryogenesis on cultured zygotic embryos of Arabidopsis: cell expansion, cell cycling, and morphogenesis during continuous exposure of embryos to 2,4-D. Am J Bot 2004, 91:1743-1756.

27. García-Martín G, Manzanera JA, González-Benito ME: Effect of exogenous $A B A$ on embryo maturation and quantification of endogenous levels of ABA and IAA in Quercus suber somatic embryos. PCTOC 2005, 80:171-177.

28. Prem D, Solís MT, Bárány I, Rodríquez-Sanz H, Risueño MC, Testillano PS: A new microspore embryogenesis system under low temperature which mimics zygotic embryogenesis initials, expresses auxin and efficiently regenerates doubled-haploid plants in Brassica napus. BMC Plant Biol 2012, 12:127.

29. Massonneau A, Coronado MJ, Audran A, Bagniewska-Zadworna A, Mol R Testillano PS, Goralski G, Dumas C, Risueño MC, Matthys-Rochon E: Multicellular structures that develop during in vitro maize pollen embryogenesis express both endosperm- and embryo-specific genes: which is which? Eur J Cell Biol 2005, 84:663-675.

30. Gómez-Garay A, López JA, Camafeita E, Bueno MA, Pintos B: Proteomic perspective of Quercus suber somatic embryogenesis. J Proteomics 2013, 93:314-325

31. Gómez-Garay A, López JA, Pintos B, Camafeita E, Bueno MA: Proteomic analysis from haploid and diploid embryos of Quercus suber $L$. identifies qualitative and quantitative differential expression patterns.

Proteomics 2009, 9:4355-4367.

32. Valledor L, Hasbún R, Meijón M, Rodríguez J, Santamaría E, Viejo M, Berdasco M, Feito I, Fraga M, Cañal MJ, Rodríguez R: Involvement of DNA methylation in tree development and micropropagation. PCTOC 2007, 91:75-86.

33. Meijón M, Valledor L, Santamaría E, Testillano PS, Risueño MC, Rodríguez R, Feito I, Cañal MJ: Epigenetic characterization of the vegetative and floral stages of azalea buds: dynamics of DNA methylation and histone $\mathrm{H} 4$ acetylation. J Plant Physiol 2009, 166:1624-1636.

34. Testillano PS, Solís MT, Risueño MC: The 5-methyl-deoxy-cytidine (5mdC) localization to reveal in situ the dynamics of DNA methylation chromatin pattern in a variety of plant organ and tissue cells during development. Physiol Plantarum 2013, 149:104-113.

35. Viejo M, Rodríguez R, Valledor L, Pérez M, Cañal MJ, Hasbún R: DNA methylation during sexual embryogenesis and implications on the induction of somatic embryogenesis in Castanea sativa Miller. Sex Plant Reprod 2010, 23:315-323.

36. Solís MT, Chakrabarti N, Corredor E, Cortés-Eslava J, Rodríguez-Serrano M, Biggiogera M, Risueño MC, Testillano PS: Epigenetic changes accompany developmental programmed cell death in tapetum cells. Plant Cell Physiol 2014, 55:16-29.

37. Chapman A, Blervacq AS, Vasseur J, Hilbert JL: Arabinogalactan-proteins in Cichorium somatic embryogenesis: effect of beta-glucosyl Yariv reagent and epitope localisation during embryo development. Planta 2000, 211:305-314.

38. van Hengel AJ, Tadesse Z, Immerzeel P, Schols H, van Kammen A, de Vries SC: $\mathrm{N}$-acetylglucosamine and glucosamine-containing arabinogalactan proteins control somatic embryogenesis. Plant Physiol 2001, 125:1880-1890.

39. Hasegawa Y, Nakamura S, Uheda E, Nakamura N: Immunolocalization and possible roles of pectins during pollen growth and callose plug formation in angiosperms. Grana 2000, 39:46-55.

40. Solís MT: Stress-induced Pollen Reprogramming to Embryogenesis: Cell Identity, Programmed Cell Death and the Role of DNA Methylation, PhD Thesis. Madrid, Spain: Department of Genetics, Complutense University of Madrid; 2012.

41. Petrášek J, Friml J: Auxin transport routes in plant development. Development 2009, 136:2675-2688.

42. Manzanera JA, Astorga R, Bueno MA: Somatic embryo induction and germination in Quercus suber L. Silvae Genet 1993, 42:2-3.

43. Bueno MA, Gómez A, Boscaiu M, Manzanera JA, Vicente O: Stress-induced formation of haploid plants through anther culture in cork oak (Quercus suber). Physiol Plantarum 1997, 99:335-341.

44. Robert HS, Grones P, Stepanova AN, Robles LM, Lokerse AS, Alonso JM, Weijers D, Friml J: Local auxin sources orient the apical-basal axis in Arabidopsis embryos. Curr Opin Plant Biol 2013, 23:2506-2512.
45. Himanen K, Boucheron E, Vanneste S, de Almeida Engler J, Inze D, Beeckman T: Auxin-mediated cell cycle activation during early lateral root initiation. Plant Cell 2002, 14:2339-2351.

46. Prasad K, Dhonukshe P: Polar Auxin Transport: Cell Polarity to Patterning. In Polar Auxin Transport. Signalling and Communication in Plants. Vol 17. Edited by Chen R, Baluska F. Berlin, Heidelberg: Springer-Verlag; 2013:25-44.

47. Larsson E, Sitbon F, Ljung K, von Arnold S: Inhibited polar auxin transport results in aberrant embryo development in Norway spruce. New Phytol 2008, 177:356-366.

48. Pintos B, Manzanera JA, Bueno MA: Cytological analysis of early microspore divisions leading to gametic embryo formation in Quercus suber L. anther cultures. Acta Physiologiae Plantarum 2005, 27:703-708.

49. Sommer HE, Brown CL, Kormanik PP: Differentiation of plantlets in longleaf pine Pinus palustris Mill. Tissue cultured in vitro. Bot Gaz 1975, 136:196-200.

50. Murashige T, Skoog F: A revised medium for rapid growth and bio assays with tobacco tissue cultures. Physiol Plantarum 1962, 15:473-497.

51. Bueno MA, Astorga R, Manzanera JA: Plant regeneration through somatic embryogenesis in Quercus suber. Physiol Plant 1992, 85:30-34.

doi:10.1186/s12870-014-0224-4

Cite this article as: Rodríguez-Sanz et al:: Early markers are present in both embryogenesis pathways from microspores and immature zygotic embryos in cork oak, Quercus suber L. BMC Plant Biology 2014 14:224.

\section{Submit your next manuscript to BioMed Central and take full advantage of:}

- Convenient online submission

- Thorough peer review

- No space constraints or color figure charges

- Immediate publication on acceptance

- Inclusion in PubMed, CAS, Scopus and Google Scholar

- Research which is freely available for redistribution

Submit your manuscript at www.biomedcentral.com/submit
C Biomed Central 